\title{
Diabetes knowledge among Croatian non-medical high school and university students
}

\author{
Kristina Blaslov • Nikolina Brcina
}

Received: 2 April 2013 / Accepted: 22 November 2013 / Published online: 6 December 2013

(C) Research Society for Study of Diabetes in India 2013

Dear Editor,

The prevalence of diabetes mellitus in Croatia is about $6.1 \%$ in the age group of $18-65 ; 92 \%$ have type 2 diabetes mellitus (T2DM) while about $40 \%$ are left undiagnosed [1]. Since there is a world trend of emerging prevalence of T2DM among youth which could be preventable by lifestyle modification [2], we estimated the current knowledge about diabetes, risk factors, symptoms and complications, treatment and management among young population (16-24 years) of nonmedical high school and university students in Croatia capital, Zagreb. According to the "convenience sampling" method using the questionnaire with closed ended questions consisted of six items we studied $67(27.2 \%)$ high school and 179 $(72.8 \%)$ university students. Two hundred and thirty students $(93.5 \%)$ gave the correct answer regarding the diabetes definition while only $12(4.9 \%)$ did not know what it was. Two hundred and nineteen $(88.9 \%)$ show the awareness that diabetes can affect everybody regardless of genetics, age or lifestyle and 192 (78 \%) find it a non-curable state. Eighty two $(33.3 \%)$ participants consider insulin as only and sufficient diabetes management instrument, while 129 (52.4\%) find diet, physical activity and other medications also to be important. Chronic diabetic complications are considered to be blindness, chronic kidney disease, cardiovascular disease and sensation difficulties all together by 163 (66.3\%) of the participants. University students have higher rate of correct answers regarding what is diabetes $(P=0.014)$, treatment

\footnotetext{
K. Blaslov $(\bowtie)$

Vuk Vrhovac Clinic for Diabetes, Endocrinology and Metabolic Diseases, University Hospital Merkur, University of Zagreb, School of Medicine, Dugi Dol 4a, Zagreb, Croatia

e-mail: kblaslov@gmail.com

N. Brcina

Health Center Zagreb-East, Zagreb, Croatia
}

regiments $(P<0.001)$ and disease complications $(P<0.001)$ compared to high-school students. Our results clearly show that the young population of non-medical students is generally well informed regarding the definition of the disease while they do not seem to be as well informed considering the topics on the symptomatology and treatment options as previously reported among university students enrolled in non-health care related professional courses in the United Arab Emirates [3]. The positive correlation of age and academic achievement observed in our population is partially in accordance with with Angeles-Llerenas et al. (2005) who reported the positive correlation of diabetes knowledge with age and education of students' mothers [4]. In order to act in the right way on insufficient knowledge and misconception to this global-burden disease proper educational programs should be developed. We do believe that educational programs should be pointed out on risk factors and prevention, because education will lead to the formation of proper attitude.

Conflict of interest None

\section{References}

1. Metelko Ž, Pavlić Renar I, Poljičanin T, Szirovitza L, Turek S. Prevalence of diabetes mellitus in Croatia. Diabetes Res Clin Pract. 2008;81:263-7.

2. Rosenbloom AL, Joe JR, Young RS, Winter WE. Emerging epidemic of type 2 diabetes in youth. Diabetes Care. 1999;22:345-54.

3. Khan N, Gomathi KG, Shehnaz SI, Muttappallymyalil J. Diabetes mellitus-related knowledge among university students in Ajman, United Arab Emirates. Sultan Qaboos Univ Med J. 2012;12:306-14.

4. Angeles-Llerenas A, Carbajal-Sánchez N, Allen B, Zamora-Muñoz S, Lazcano-Ponce E. Gender, body mass index and socio-demographic variables associated with knowledge about type 2 diabetesmellitus among 13,293 Mexican students. Acta Diabetol. 2005;42:36-45. 